\title{
Surface topography and ice flow in the vicinity of the EDML deep-drilling site, Antarctica
}

\author{
Christine WESCHE, ${ }^{1}$ Olaf EISEN, ${ }^{1,2}$ Hans OERTER, ${ }^{1}$ Daniel SCHULTE, ${ }^{1}$ \\ Daniel STEINHAGE ${ }^{1}$
}

\author{
${ }^{1}$ Alfred Wegener Institute for Polar and Marine Research, PO Box 120161, D-27515 Bremerhaven, Germany \\ E-mail: christine.wesche@awi.de \\ ${ }^{2}$ Laboratory of Hydraulics, Hydrology and Glaciology (VAW), ETH Zürich, CH-8092 Zürich, Switzerland
}

\begin{abstract}
Interpretation of ice-core records requires accurate knowledge of the past and present surface topography and stress-strain fields. The European Project for Ice Coring in Antarctica (EPICA) drilling site $\left(75.0025^{\circ} \mathrm{S}, 0.0684^{\circ} \mathrm{E} ; 2891.7 \mathrm{~m}\right)$ in Dronning Maud Land, Antarctica, is located in the immediate vicinity of a transient and forking ice divide. A digital elevation model is determined from the combination of kinematic GPS measurements with the GLAS12 datasets from the ICESat. Based on a network of stakes, surveyed with static GPS, the velocity field around the drilling site is calculated. The annual mean velocity magnitude of 12 survey points amounts to $0.74 \mathrm{~m} \mathrm{a}^{-1}$. Flow directions mainly vary according to their distance from the ice divide. Surface strain rates are determined from a pentagonshaped stake network with one center point close to the drilling site. The strain field is characterized by along-flow compression, lateral dilatation and vertical layer thinning.
\end{abstract}

\section{INTRODUCTION}

Within the framework of the European Project for Ice Coring in Antarctica (EPICA) a deep ice core (EDML) was drilled in Dronning Maud Land (DML), Antarctica, near the German summer station, Kohnen (EPICA Community Members, 2006). To obtain high-resolution climate information of the last glacial cycle, a drilling site was chosen that provides comparatively high accumulation rates, large ice thickness and nearly undisturbed layering of the ice. The EDML drilling site $\left(75.0025^{\circ} \mathrm{S}, 0.0684^{\circ} \mathrm{E} ; 2891.7 \mathrm{~m}\right.$ above the World Geodetic System 1984 (WGS84) ellipsoid) is located in the Atlantic sector of Antarctica (Fig. 1) and is used to investigate the connection between Northern and Southern Hemisphere climate variability in the past. The area surrounding the EDML drilling site is situated between two transient ice divides which fork at approximately $75.1^{\circ} \mathrm{S}$, $1^{\circ} \mathrm{E}$, according to the elevation model of Bamber and Bindschadler (1997). The deep ice-core drilling was carried out in the austral summer seasons 2000/01 to 2005/06. The ice thickness in this region is $2782 \pm 5 \mathrm{~m}$, as measured by airborne radio-echo sounding, and the total recovered core length was $2774.15 \mathrm{~m}$ (personal communication from F. Wilhelms, 2006). The drilling finished when subglacial water entered the borehole. The recent accumulation rate in the surroundings of the EDML drilling site is $64 \mathrm{~kg} \mathrm{~m}^{-2} \mathrm{a}^{-1}$ (Eisen and others, 2005), with small-scale spatial variability of $\sim 10 \%$.

Accurate interpretation of the EDML ice-core data (e.g. past accumulation from annual layer thicknesses) requires knowledge of the complete strain field to correct for dynamic layer thickness variation. In this paper, we determine the topography, flow and strain field in the wider surroundings of the drilling site. Similar investigations were previously made at several drilling sites in Antarctica and Greenland. For example, Vittuari and others (2004) present a velocity field at Dome C (the first EPICA deep-drilling site (EPICA Community Members, 2004)) in the Indo-Pacific sector of the Antarctic ice sheet. In Greenland, Hvidberg and others (2002) investigated the ice flow at NorthGRIP, a drilling site that is also located in the vicinity of a transient ice divide. For the EDML site, a digital elevation model (DEM) is derived from the combination of ground-based kinematic GPS (global positioning system) and ICESat (Ice, Cloud and land Elevation Satellite) laser altimetry, providing highly accurate surface topography in the region of interest. This forms, together with ice velocity data, the basis for estimating and interpreting deformation in the upper part of the ice sheet.

\section{DATA AND METHODS}

Static and kinematic GPS measurements were used for our investigation. The elevation data derived from the kinematic GPS data were complemented by NASA's ICESat satellite laser altimetry data (US National Snow and Ice Data Center (NSIDC) http://nsidc.org/data/icesat/).

\section{Kohnen Reference Station (KRS)}

Kohnen Reference Station (KRS), which is located at the German summer station Kohnen $\left(75.0018^{\circ} \mathrm{S}, 0.0667^{\circ} \mathrm{E}\right)$, is used for processing our GPS measurements. This is a nonpermanent GPS station, providing data at $1 \mathrm{~s}$ intervals only during the drilling campaigns 2000/01 to 2005/06 (with interruptions in the season 2004/05). The KRS GPS antenna was mounted on the northern corner of the Kohnen station. With the aid of the International Global Navigation Satellite Systems Service (IGS) network, the daily position of KRS was determined using the GPS stations Mawson, Sanae IV, Syowa, Davis, Casey and O'Higgins (Fig. 1). The KRS positions were determined with the post-processing software GAMIT, assuming motion of the site was negligible during the processing window (Scripps Institution of Oceanography, http://sopac.ucsd.edu/processing/gamit/).

\section{Surface profiles from kinematic GPS measurements}

Kinematic GPS measurements combined with groundpenetrating radar (GPR) recorded during the 2000/01 field campaign (Eisen and others, 2005) form the basis for generating a DEM with a higher accuracy and resolution 


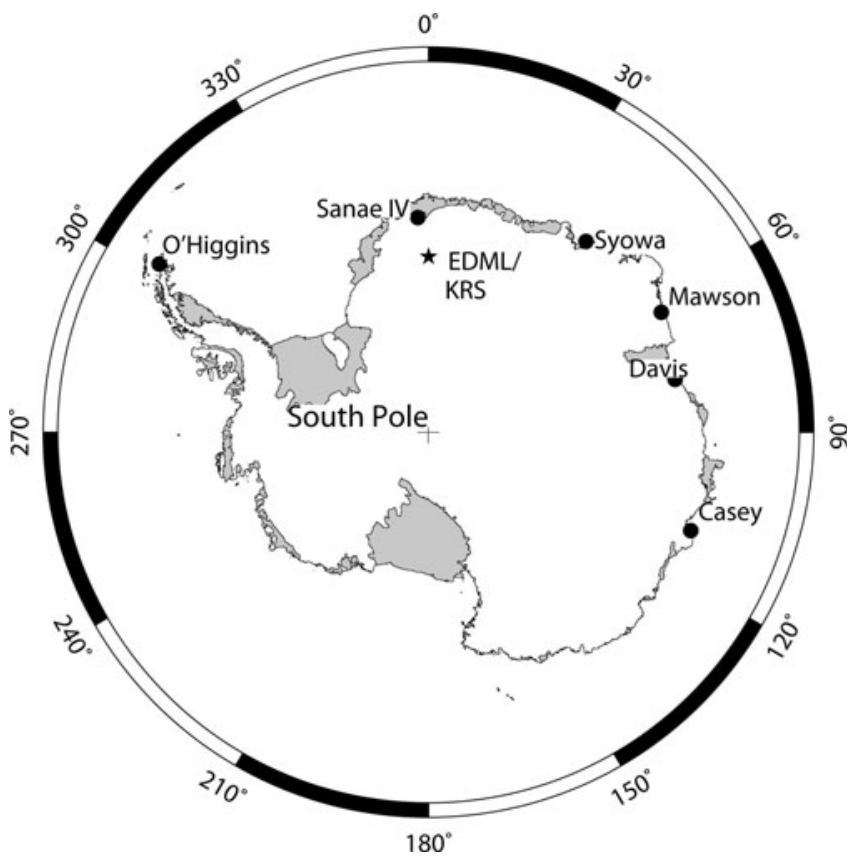

Fig. 1. Location map of the EDML drilling site in Antarctica, marked with a star. Six International Global Navigation Satellite Systems Service (IGS) reference stations are indicated with filled circles. They were used for determining the position of the local reference point Kohnen Reference Station (KRS) adjacent to the EDML drilling site.

than former DEMs in the surroundings of the EDML drilling site. A Trimble SSI 4000 GPS receiver was mounted on a snowmobile which was navigated at a velocity of about $10 \mathrm{~km} \mathrm{~h}^{-1}$ along predefined tracks (Fig. 2, solid lines) in the area of investigation $\left(74.8-75.1^{\circ} \mathrm{S}, 0.2^{\circ} \mathrm{W}-0.8^{\circ} \mathrm{E}\right)$. There are two networks of kinematic GPS profiles, both centered on the EDML drilling site. The length of the edges of the first grid is $10 \mathrm{~km}$ with a profile spacing of $1-3 \mathrm{~km}$. The second grid is a star-like pattern, which consists of seven $20-25 \mathrm{~km}$ legs. The kinematic GPS data were processed with Trimble Geomatics Office $^{\mathrm{TM}}\left(\mathrm{TGO}^{\mathrm{TM}}\right)$, including precise ephemeris and ionosphere-free solution.

\section{Flow and strain networks using static GPS measurements}

In order to determine horizontal velocities and strain rates, static GPS measurements around the EDML drilling site were carried out with Ashtech Z-12 and Trimble SSI 4000 GPS receivers in the austral summer seasons between 1999/2000 and 2005/06. For the velocity network 13 points in the surroundings of the EDML drilling site were used (Fig. 2). These points are marked with aluminium stakes and were surveyed for approximately 1 hour per season to find their positions. The static GPS data were also processed with $\mathrm{TGO}^{\mathrm{TM}}$. All determined positions are available in the PANGAEA database (doi: 10.1594/PANGAEA.611331).

\section{Surface profiles from satellite altimetry}

The Geoscience Laser Altimeter System (GLAS) on board NASA's ICESat provides global altimetry data with a wavelength of $1064 \mathrm{~nm}$ up to $86^{\circ} \mathrm{N}$ and $86^{\circ} \mathrm{S}$. The laser footprint has a diameter of $60 \mathrm{~m}$, and the along-track distance between the footprints is $172 \mathrm{~m}$. The positioning error is $35 \mathrm{~m}$ (Zwally and others, 2002). In this paper, GLAS12 altimetry data for the periods L1a (20 February to 20 March 2003) and L2a

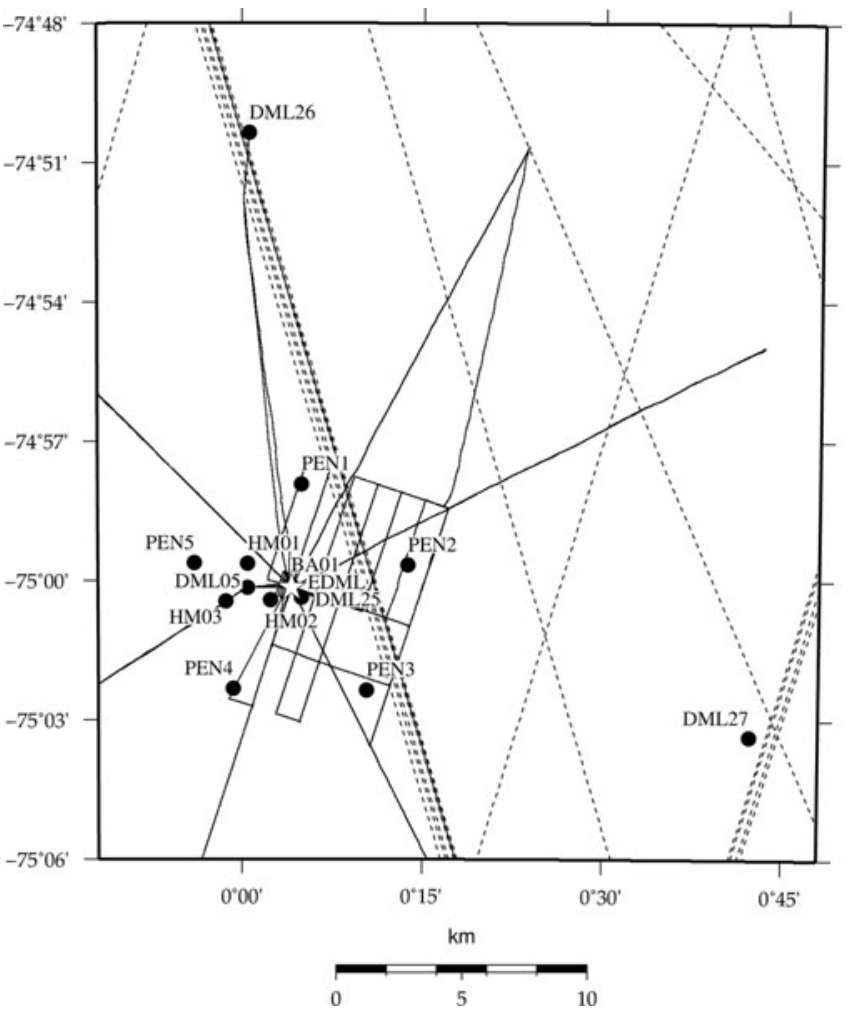

Fig. 2. Data coverage for the DEM derived in the present study. The solid lines present the kinematic GPS profiles, and the dotted lines the ICESat GLAS12 ground tracks. Sites used for static GPS measurements are marked with filled circles; the star marks the EDML drilling site.

(25 September to 18 November 2003) are used to determine the surface elevation model of the investigated area. The ground tracks of these measurements across the investigated area are plotted in Figure 2 as dotted lines. The GLAS12 satellite laser altimetry data and the corresponding NSIDC GLAS Altimetry elevation extractor Tool (NGAT) are provided by NSIDC (http://nsidc.org/data/icesat/).

\section{DATA ACCURACY}

Knowledge of potential errors is essential for determining the quality of the kinematic and static GPS data. The general GPS errors and those of our solutions are presented in this section. The distance between the reference station and the survey point or profile is the principal factor affecting the accuracy of the position to be determined.

\section{GPS errors}

GPS observations at high latitudes are affected by the relatively weak satellite geometry, and hence formal errors are larger here than at other latitudes. Ionospheric and tropospheric effects were minimized by adopting the ionosphere-free linear combination and applying a tropospheric model. Further error reduction occurs through the double-differencing approach used in $\mathrm{TGO}^{\mathrm{TM}}$ and the relatively short baselines.

\section{Kinematic GPS measurements}

Since we used KRS, located in the center of the kinematic GPS profiles, systematic positioning errors are negligible. The accuracy of the kinematic GPS measurements is 


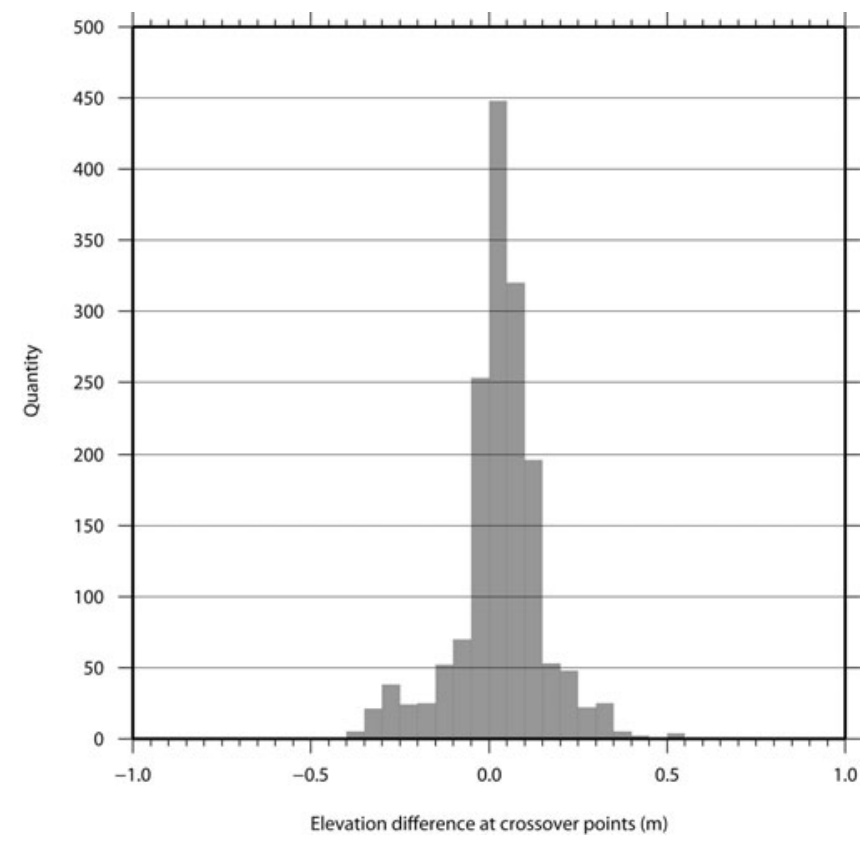

Fig. 3. Histogram of elevation differences at 1615 crossover points of the surveyed kinematic GPS profiles.

estimated by a crossover-point analysis. The histogram in Figure 3 shows the elevation differences at the 1615 crossover points. The mean elevation difference is $0.03 \mathrm{~m}$ with a standard deviation of $0.12 \mathrm{~m}$.

\section{Static GPS measurements}

All stakes (Fig. 2) were occupied for an observation period of $\sim 1$ hour in several campaigns. The length of the baselines to KRS varied between $0.03 \mathrm{~km}$ (BA01) and $19.4 \mathrm{~km}$ (DML27). The positions of all stakes were computed using $\mathrm{TGO}^{\mathrm{TM}}$, and the formal horizontal and vertical errors (Table 1) were derived for every point in a processing report. The formal errors issued by GPS software are usually over-optimistic. Experience shows that these errors need to be scaled by a factor of 5-20, to be closer to the true uncertainty of the static GPS (personal communication from M. King, 2007). We take a factor of 20 as a conservative estimate of the precision of the GPS positions. As the accuracy depends on the baseline length, we use the points BA01 and DML27 to estimate the accuracy of the static GPS measurements.

The positions of these two points were calculated against KRS for two campaigns. They have quite different horizontal and vertical errors, which can be attributed to the longer

Table 1. Error estimates for BA01 and DML27

\begin{tabular}{lcccc}
\hline Point & Campaign & $\begin{array}{c}\text { Horizontal } \\
1-\sigma \text { error* }\end{array}$ & $\begin{array}{c}\text { Vertical } \\
1-\sigma \text { error* }\end{array}$ & $\begin{array}{c}\text { Baseline } \\
\text { length }\end{array}$ \\
& & $\mathrm{m}$ & $\mathrm{m}$ & $\mathrm{m}$ \\
\hline BA01 & $2002 / 03$ & 0.01 & 0.04 & 29.4 \\
BA01 & $2005 / 06$ & 0.01 & 0.02 & 29.7 \\
DML27 & $2002 / 03$ & 0.30 & 0.82 & 19359.7 \\
DML27 & $2005 / 06$ & 0.04 & 0.10 & 19358.9
\end{tabular}

*Based on formal errors issued by the GPS software, TGO ${ }^{\text {TM }}$, scaled by a factor of 20 .
Table 2. Calculated mean annual horizontal ice-flow velocities

\begin{tabular}{cccc}
\hline Point & $\begin{array}{c}\text { Magnitude } \\
\mathrm{m} \mathrm{a}^{-1}\end{array}$ & Direction & Period of averaging \\
& $\circ$ & \\
\hline
\end{tabular}

\begin{tabular}{llll}
\hline BA01 & 0.682 & 272.6 & Jan. 2003-Dec. 2005 \\
DML05 & 0.660 & 270.4 & Jan. 2001-Dec. 2005 \\
DML25 & 0.830 & 274.2 & Jan. 2004-Dec. 2005 \\
DML26 & 1.066 & 335.9 & Jan. 2001-Dec. 2005 \\
DML27 & 0.963 & 287.5 & Feb. 2003-Dec. 2005 \\
HM01 & 0.642 & 273.7 & Jan. 2000-Dec. 2005 \\
HM02 & 0.684 & 270.0 & Jan. 2000-Dec. 2005 \\
HM03 & 0.674 & 266.6 & Jan. 2000-Dec. 2005 \\
PEN1 & 0.643 & 291.3 & Jan. 2000-Dec. 2005 \\
PEN2 & 0.767 & 282.9 & Jan. 2000-Dec. 2005 \\
PEN3 & 0.859 & 265.9 & Jan. 2000-Dec. 2005 \\
PEN4 & 0.841 & 257.9 & Jan. 2000-Dec. 2005 \\
PEN5 & 0.624 & 269.8 & Jan. 2000-Dec. 2005
\end{tabular}

baseline length between KRS and DML27. However, there are also significant differences between campaigns for the same point. For DML27, the horizontal and vertical errors in 2002/03 are almost an order of magnitude larger than in $2005 / 06$. This may stem from the high sunspot activity in 2002/03 (http://solarscience.msfc.nasa.gov/SunspotCycle. shtml) in combination with the baseline length, despite using the ionosphere-free solution of $\mathrm{TGO}^{\mathrm{TM}}$. We assume that the maximum horizontal and vertical errors for our solutions are given by the values for DML27 of $0.30 \mathrm{~m}$ and $0.82 \mathrm{~m}$, respectively, from the campaign in 2002/03.

\section{GLAS data}

ICESat's positioning precision is stated as $35 \mathrm{~m}$ and the predicted elevation data accuracy is $0.15 \mathrm{~m}$ (Zwally and others, 2002). Shuman and others (2006) presented a new elevation accuracy assessment of $\sim 0.02 \mathrm{~m}$ for low-slope and clear-sky conditions. Our area of investigation is a low-slope region, but clouds during the observation period cannot be excluded over the whole period. The elevation measurements of the ICESat laser altimeter refer to the TOPEX/ Poseidon ellipsoid. Differences in elevation between the TOPEX/Poseidon ellipsoid and the WGS84 ellipsoid are approximately $0.71 \mathrm{~m}$ in the region of interest (personal communication from T. Haran, 2005). When transforming to the WGS84 ellipsoid we subtract this value from all GLAS12 elevation data.

\section{RESULTS}

\section{Surface topography}

The derived surface topography in the area of investigation refers to the WGS84 ellipsoid and is a combination of the GPS and the GLAS12 datasets (Fig. 4, contours). A crossover-point analysis was performed before combining the datasets to identify systematic offsets and to estimate the uncertainties. As crossover points for the GPS data we use the average of all GPS measurements within the diameter of the GLAS footprint of about $60 \mathrm{~m}$. Considering all crossover points, the GLAS12 data (transformed to the WGS84 ellipsoid) are found to be $0.119 \mathrm{~m}$ lower than the GPS data, on average. This elevation difference was added to the GLAS12 data, i.e. we corrected the elevations to the GPS 


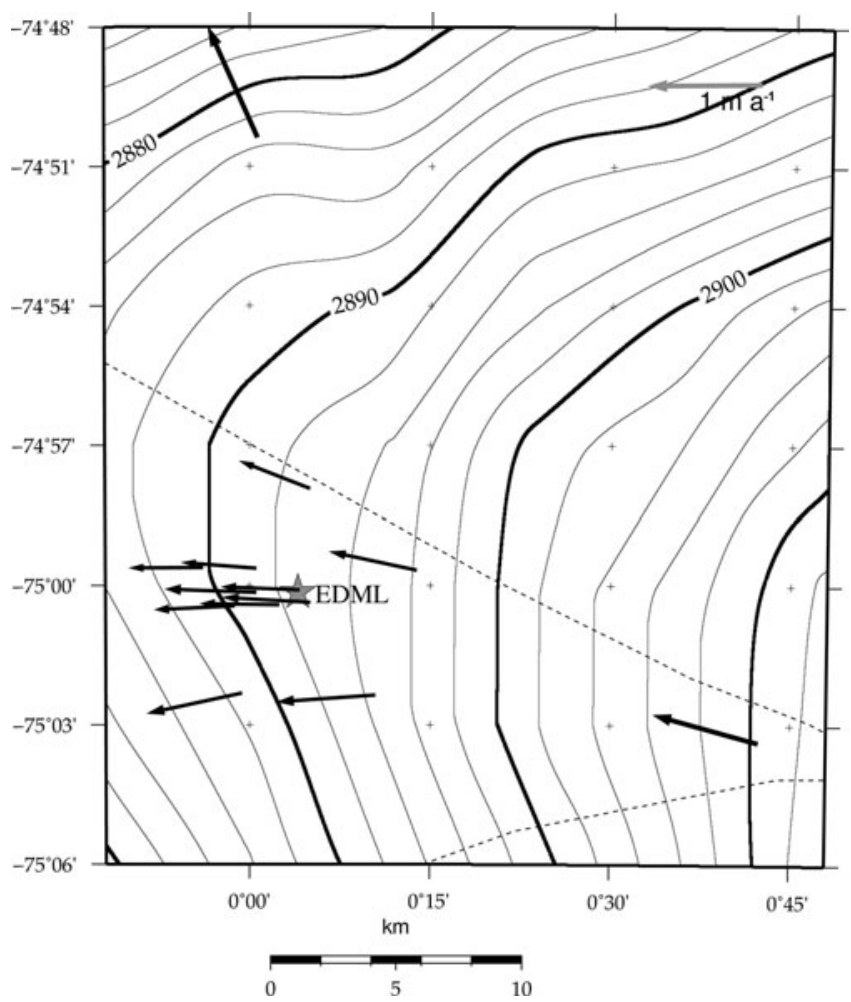

Fig. 4. Surface flow-velocity vectors in the area of interest, plotted on the contour map of the combined and gridded $(5 \mathrm{~km} \times 5 \mathrm{~km})$ GPS/GLAS12 elevation model. The contour interval is $2 \mathrm{~m}$. The dotted curves indicate the ice divide corresponding to the DEM of Bamber and Bindschadler (1997).

profiles. To get sufficient spatial coverage of elevation data over the whole area of investigation, we interpolated the combined dataset with a minimum-curvature algorithm (Wessel and Smith, 1991) on a $5 \mathrm{~km} \times 5 \mathrm{~km}$ grid (Fig. 4). With this grid size, at least one data point was available for each gridcell, even several tens of kilometers away from the drilling site.

\section{Surface velocity}

The velocity magnitude at the survey points between the two ice divides varies between $0.62 \mathrm{~m} \mathrm{a}^{-1}$ (PEN5) and $0.96 \mathrm{~m} \mathrm{a}^{-1}$ (DML27). The flow direction varies between $257.9^{\circ}$ (PEN4) and $291.3^{\circ}$ (PEN1). The flow velocity of DML26, north of the divide, is outside this range, moving in a direction of $335.9^{\circ}$ with a magnitude of $1.07 \mathrm{~m} \mathrm{a}^{-1}$ (Table 2; Fig. 4).

The location of the EDML drilling site was surveyed on 10 January 2001, before the drilling operation started, yielding $75.0025^{\circ} \mathrm{S}, 0.068^{\circ} \mathrm{E}$ and $2891.7 \mathrm{~m}$ at the snow surface. As excavation of the drill trench does not allow accurate remeasurements, we use the mean velocities of the points next to it, DML25 and BA01. We thus obtain a value of $0.756 \mathrm{~m} \mathrm{a}^{-1}$ in the direction of $273.4^{\circ}$ for the ice velocity at the drilling site. The precision of the velocity measurements differs, depending on the period and data used (see Table 1). We therefore perform a propagation of errors by

$$
\delta v^{2}=\left(\frac{v}{s} \delta s_{\mathrm{m}}\right)^{2}+\left(\frac{v}{t} \delta t\right)^{2}
$$

Only the horizontal errors are used; the vertical errors are neglected for calculating the propagated error $(\delta v)$ of the annual movement. Here, $v$ is the velocity magnitude and

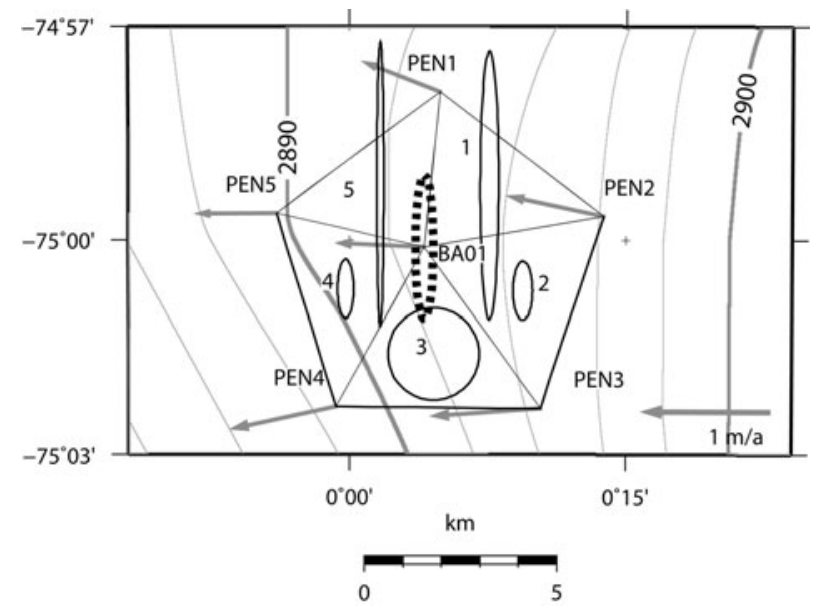

Fig. 5. Velocity vectors of the pentagon-shaped network (PEN1PEN5) and BA01. Strain ellipses are plotted for the five strain triangles, indicated by numbers 1-5. The mean strain ellipse (dotted) is centered on BA01. See text for the calculation of the mean strain ellipse. The elevation contour interval is $2 \mathrm{~m}$.

$s$ the horizontal offset of the survey point over the measurement interval $(t)$. The term $\delta s_{\mathrm{m}}$ is the mean of the horizontal errors for the survey point of the two campaigns used for the determination of the velocities. The time error, $\delta t$, is assumed to be a constant of 1 day ( $1 / 365.25$ years), because the start and end time is rounded by the day. The resulting errors for sites DML27 and BA01 are 0.059 and $0.003 \mathrm{~m} \mathrm{a}^{-1}$, respectively. As discussed above, we take the error at DML27 as the maximum error of the velocity determination, as it has the longest baseline.

\section{Surface strain rates}

Strain rates were determined from a pentagon-shaped network (PEN1-PEN5) with BA01 as the center reference pole (Fig. 5). Using the horizontal surface velocities in Table 2, with the geodetical nomenclature of $y$ as the eastward and $x$ as the northward components, we determine the strain-rate components from (Paterson, 1994)

$$
\dot{\varepsilon}_{x}=\frac{\Delta v_{x}}{\Delta x}, \quad \dot{\varepsilon}_{y}=\frac{\Delta v_{y}}{\Delta y},
$$

and the combined strain rate as

$$
\dot{\varepsilon}_{x y}=\frac{1}{2}\left(\frac{\Delta v_{x}}{\Delta y}+\frac{\Delta v_{y}}{\Delta x}\right),
$$

where $\Delta v_{x}$ and $\Delta v_{y}$ are the differences of the $x$ and $y$ velocity components of the considered pair of survey points, and $\Delta x$ and $\Delta y$ are the distances between the stakes in the $x$ and $y$ directions. Distances from the reference pole to each pentagon point vary between $3961.85 \mathrm{~m}$ (BA01-PEN5) and 5173.28 m (BA01-PEN3). Using Equation (3) the combined surface strain rate is calculated for every pair of neighboring points (west-east and south-north), yielding ten values (Table 3).

To determine the strain rates, we divide the pentagon into five strain triangles (Fig. 5) and assume the strain is constant over the area of the triangle. We calculate the average of the strain for each triangle (e.g. the mean of BA01/PEN1, BA01/ PEN2 and PEN1/PEN2 for the northeastern triangle, numbered 1). The principal components are calculated using the 
Table 3. Strain rates for pairs of survey points

\begin{tabular}{|c|c|c|c|c|c|c|c|}
\hline Pair of points & $\begin{array}{l}\dot{\varepsilon}_{x y} \\
\mathrm{a}^{-1}\end{array}$ & $\begin{array}{c}\dot{\varepsilon}_{x} \\
\mathrm{a}^{-1}\end{array}$ & $\begin{array}{l}\delta \dot{\varepsilon}_{x} \\
\mathrm{a}^{-1}\end{array}$ & $\begin{array}{c}\dot{\varepsilon}_{y} \\
\mathrm{a}^{-1}\end{array}$ & $\begin{array}{l}\delta \dot{\varepsilon}_{y} \\
\mathrm{a}^{-1}\end{array}$ & $\begin{array}{c}\Delta v_{x} \\
\mathrm{ma}^{-1}\end{array}$ & $\begin{array}{c}\Delta v_{y} \\
\mathrm{ma}^{-1}\end{array}$ \\
\hline BA01/PEN1 & $-2.20 \times 10^{-4}$ & $-2.02 \times 10^{-5}$ & $1.47 \times 10^{-5}$ & $-9.61 \times 10^{-4}$ & $2.85 \times 10^{-4}$ & -0.08 & -0.20 \\
\hline BA01/PEN2 & $-5.44 \times 10^{-5}$ & $6.73 \times 10^{-5}$ & $5.83 \times 10^{-5}$ & $-2.74 \times 10^{-5}$ & $1.29 \times 10^{-5}$ & 0.07 & -0.13 \\
\hline BA01/PEN3 & $-1.57 \times 10^{-5}$ & $-4.35 \times 10^{-5}$ & $1.49 \times 10^{-5}$ & $2.86 \times 10^{-5}$ & $1.86 \times 10^{-5}$ & -0.18 & 0.09 \\
\hline BA01/PEN4 & $-5.81 \times 10^{-5}$ & $-3.32 \times 10^{-5}$ & $1.41 \times 10^{-5}$ & $-9.90 \times 10^{-5}$ & $2.87 \times 10^{-5}$ & -0.14 & -0.21 \\
\hline BA01/PEN5 & $-3.12 \times 10^{-5}$ & $-8.24 \times 10^{-5}$ & $8.63 \times 10^{-5}$ & $-8.49 \times 10^{-5}$ & $1.54 \times 10^{-5}$ & -0.06 & -0.03 \\
\hline PEN1/PEN2 & $-4.73 \times 10^{-5}$ & $-4.97 \times 10^{-5}$ & $1.97 \times 10^{-5}$ & $1.70 \times 10^{-5}$ & $1.36 \times 10^{-5}$ & -0.15 & 0.08 \\
\hline PEN1/PEN5 & $-3.79 \times 10^{-5}$ & $-7.38 \times 10^{-6}$ & $1.78 \times 10^{-5}$ & $-5.73 \times 10^{-5}$ & $1.46 \times 10^{-5}$ & -0.02 & -0.24 \\
\hline PEN2/PEN3 & $-5.96 \times 10^{-5}$ & $-2.10 \times 10^{-5}$ & $1.18 \times 10^{-5}$ & $-1.57 \times 10^{-4}$ & $4.28 \times 10^{-5}$ & -0.11 & -0.22 \\
\hline PEN3/PEN4 & $-2.71 \times 10^{-4}$ & $1.65 \times 10^{-4}$ & $2.87 \times 10^{-4}$ & $-2.16 \times 10^{-5}$ & $1.13 \times 10^{-5}$ & 0.03 & -0.11 \\
\hline PEN4/PEN5 & $-3.72 \times 10^{-5}$ & $-4.01 \times 10^{-5}$ & $1.21 \times 10^{-5}$ & $9.63 \times 10^{-5}$ & $3.32 \times 10^{-5}$ & -0.20 & 0.17 \\
\hline
\end{tabular}

Note: Combined $\left(\dot{\varepsilon}_{x y}\right)$ and directional $\left(\dot{\varepsilon}_{x}\right.$ and $\left.\dot{\varepsilon}_{y}\right)$ strain rates with conservative error estimates $\left(\delta \dot{\varepsilon}_{x}\right.$ and $\left.\delta \dot{\varepsilon}_{y}\right)$; differences of the velocity components in northsouth $\left(\Delta v_{x}\right)$ and east-west $\left(\Delta v_{y}\right)$ direction for BA01 and PEN1-PEN5. In this work, the differences of the velocity components were calculated by west minus east values, and south minus north values. Negative strain rates thus correspond to compression, and positive strain rates to extension.

rotation, $\theta$, of the $x$ and $y$ axes

$$
\tan 2 \theta=\frac{2 \dot{\varepsilon}_{x y}}{\dot{\varepsilon}_{x}-\dot{\varepsilon}_{y}}
$$

This provides one of two values for $\theta$, which are $90^{\circ}$ apart. One gives the direction of the maximum strain rate, $\dot{\varepsilon}_{\max }$, the other of minimum strain rate, $\dot{\varepsilon}_{\min }$. The strain-rate magnitudes along these directions follow from

$$
\begin{aligned}
\dot{\varepsilon}_{\max , \min }= & \dot{\varepsilon}_{x} \cos ^{2} \theta_{\max , \min }+\dot{\varepsilon}_{y} \sin ^{2} \theta_{\max , \min } \\
& +2 \dot{\varepsilon}_{x y} \sin \theta_{\max , \min } \cos \theta_{\max , \min } .
\end{aligned}
$$

This calculation is repeated for every strain triangle. The direction of maximum strain rate varies between $30.1^{\circ}$ and $75.0^{\circ}$. Using the incompressibility condition (Paterson, 1994)

$$
\dot{\varepsilon}_{x}+\dot{\varepsilon}_{y}+\dot{\varepsilon}_{z}=0,
$$

we estimate the flow-induced vertical strain rate $\dot{\varepsilon}_{z}$. It varies between $1.31 \times 10^{-6}$ and $3.79 \times 10^{-4} \mathrm{a}^{-1}$ (Table 4), with a standard variation of $6.49 \times 10^{-5} \mathrm{a}^{-1}$. To estimate a strain rate representative of the $\mathrm{EDML}$ drilling site, we determine the average horizontal deformation and its direction at BA01. For this purpose, the arithmetic means of $\dot{\varepsilon}_{x y}, \dot{\varepsilon}_{x}$ and $\dot{\varepsilon}_{y}$ from the strain triangles are calculated and used in Equations (4) and (5) (Table 4). The maximum rate is $-1.85 \times 10^{-4} \mathrm{a}^{-1}$, acting in the direction of $65.8^{\circ}$. The minimum rate, $2.32 \times 10^{-5} \mathrm{a}^{-1}$, acts in the direction of $155.8^{\circ}$. In addition to the arithmetic mean, we determine the weighted mean for the directional and vertical strain-rate components $\left(\dot{\varepsilon}_{x, y, z}\right)$, using the strain-rate error weights (Table 4). The arithmetic mean of the vertical strain rate, $\dot{\varepsilon}_{z}$, is $(1.62 \pm 1.25) \times 10^{-4} \mathrm{a}^{-1}$, and the weighted mean is $(1.09 \pm 1.25) \times 10^{-4} \mathrm{a}^{-1}$.

\section{DISCUSSION}

The DEM presented here is compared with the DEM generated by Bamber and Bindschadler (1997) from European Remote-sensing Satellite-1 (ERS-1) radar altimetry, which is also available on a $5 \mathrm{~km} \times 5 \mathrm{~km}$ grid. For comparison, we subtract the Bamber and Bindschadler (1997) DEM from our combined GPS/GLAS12 DEM. The northeastern edge of the area of investigation is striking, where the elevations of the Bamber and Bindschadler (1997) DEM are about $2 \mathrm{~m}$ higher than those in our DEM (Fig. 6). Calculating the mean difference between the combined GPS/GLAS12 DEM and the Bamber and Bindschadler (1997) DEM for

\begin{tabular}{|c|c|c|c|c|c|c|c|c|c|c|c|}
\hline \multirow{2}{*}{$\begin{array}{l}\text { Strain } \\
\text { triangle }\end{array}$} & $\dot{\varepsilon}_{x y}$ & $\dot{\varepsilon}_{x}$ & $\delta \dot{\varepsilon}_{x}$ & $\dot{\varepsilon}_{y}$ & $\delta \dot{\varepsilon}_{y}$ & $\dot{\varepsilon}_{z}$ & $\delta \dot{\varepsilon}_{z}$ & $\dot{\varepsilon}_{\max }$ & $\theta_{\max }$ & $\dot{\varepsilon}_{\text {min }}$ & \multirow{2}{*}{$\begin{array}{c}\theta_{\min } \\
\circ\end{array}$} \\
\hline & $a^{-1}$ & $a^{-1}$ & $a^{-1}$ & $a^{-1}$ & $a^{-1}$ & $a^{-1}$ & $a^{-1}$ & $a^{-1}$ & $\circ$ & $a^{-1}$ & \\
\hline 1 & $-9.30 \times 10^{-5}$ & $-8.70 \times 10^{-7}$ & $3.66 \times 10^{-5}$ & $-3.24 \times 10^{-4}$ & $1.65 \times 10^{-4}$ & $3.25 \times 10^{-4}$ & $1.69 \times 10^{-4}$ & $-3.49 \times 10^{-4}$ & 75.03 & $2.40 \times 10^{-5}$ & 165.03 \\
\hline 2 & $-4.32 \times 10^{-5}$ & $9.60 \times 10^{-7}$ & $3.54 \times 10^{-5}$ & $-5.18 \times 10^{-5}$ & $2.80 \times 10^{-5}$ & $5.09 \times 10^{-5}$ & $4.51 \times 10^{-5}$ & $-7.61 \times 10^{-5}$ & 60.71 & $2.52 \times 10^{-5}$ & 150.71 \\
\hline 3 & $-1.15 \times 10^{-4}$ & $2.94 \times 10^{-5}$ & $1.66 \times 10^{-4}$ & $-3.07 \times 10^{-5}$ & $2.08 \times 10^{-5}$ & $1.31 \times 10^{-6}$ & $1.67 \times 10^{-4}$ & $-1.20 \times 10^{-4}$ & 52.32 & $1.18 \times 10^{-4}$ & 142.32 \\
\hline 5 & $-9.63 \times 10^{-5}$ & $-3.67 \times 10^{-5}$ & $5.18 \times 10^{-5}$ & $-3.42 \times 10^{-4}$ & $1.65 \times 10^{-4}$ & $3.79 \times 10^{-4}$ & $1.73 \times 10^{-4}$ & $-3.70 \times 10^{-4}$ & 73.89 & $-8.83 \times 10^{-6}$ & 163.89 \\
\hline \multicolumn{12}{|c|}{ Arithmetic mean } \\
\hline & $-7.80 \times 10^{-5}$ & $-1.18 \times 10^{-5}$ & $3.76 \times 10^{-5}$ & $-1.50 \times 10^{-4}$ & $4.74 \times 10^{-5}$ & $1.62 \times 10^{-4}$ & $6.05 \times 10^{-5}$ & $-1.85 \times 10^{-4}$ & 65.83 & $2.32 \times 10^{-5}$ & 155.83 \\
\hline \multicolumn{2}{|c|}{ Weighted mean } & $-1.54 \times 10^{-5}$ & & $-5.64 \times 10^{-5}$ & & $1.09 \times 10^{-4}$ & & & & & \\
\hline
\end{tabular}
every $5 \mathrm{~km} \times 5 \mathrm{~km}$ gridcell, we determine a mean elevation difference of $-0.33 \mathrm{~m}$. That is, the DEM of Bamber and

Table 4. Strain rates for the strain triangles

Note: Combined $\left(\dot{\varepsilon}_{x y}\right)$, directional $\left(\dot{\varepsilon}_{x}\right.$ and $\left.\dot{\varepsilon}_{y}\right)$, vertical strain rate $\left(\dot{\varepsilon}_{z}\right)$, maximum and minimum strain rate $\left(\dot{\varepsilon}_{\max }\right.$ and $\left.\dot{\varepsilon}_{\text {min }}\right)$ and the direction of maximum and minimum strain rate $\left(\theta_{\max }\right.$ and $\left.\theta_{\min }\right)$. The conservative error estimates for the directional and vertical strain rates for the five triangles are denoted by $\delta \dot{\varepsilon}_{(x, y, z)}$. Weighted mean refers to the weighting by corresponding errors. See text for the calculation of the arithmetic and weighted means. 


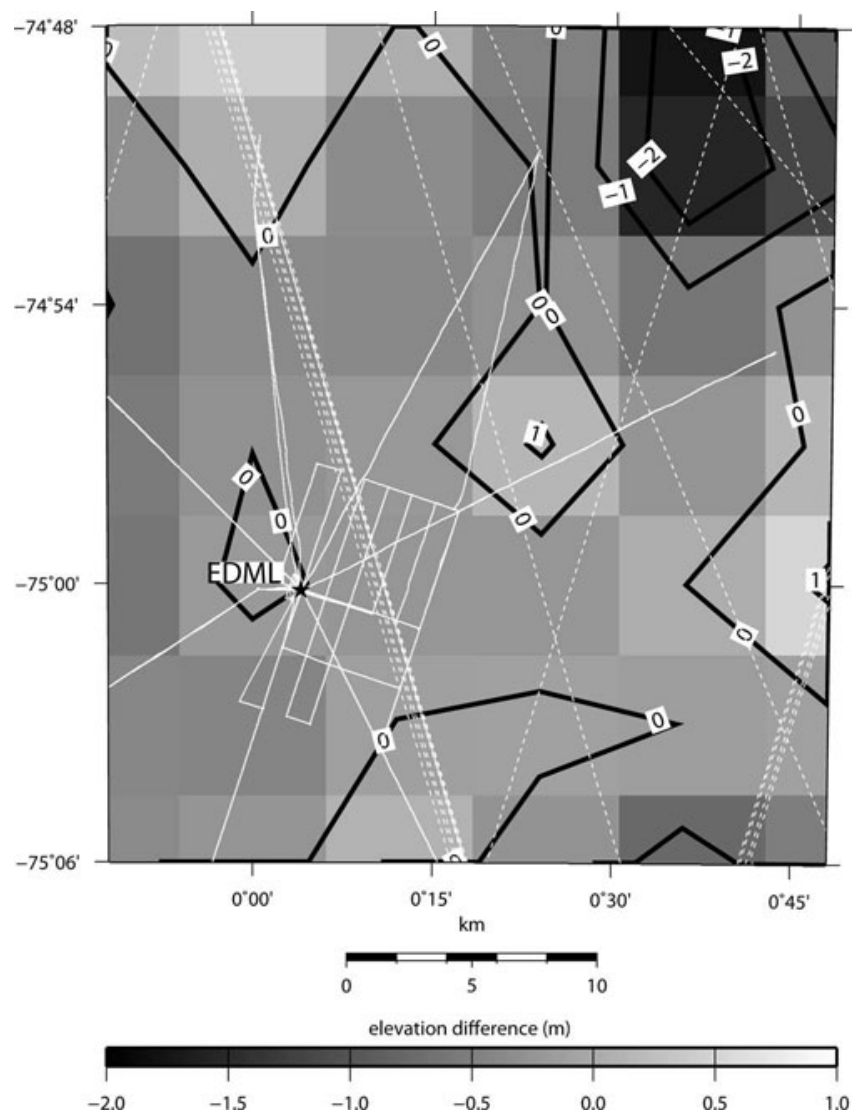

Fig. 6. Elevation differences of our GPS/GLAS12 DEM minus the Bamber and Bindschadler (1997) DEM. The contour interval is $1 \mathrm{~m}$. Kinematic GPS and GLAS12 data coverage used in this paper (Fig. 2) are plotted as white dotted (GLAS12) and solid (GPS) lines.

Bindschadler (1997) is about $0.3 \mathrm{~m}$ higher than our combined GPS/GLAS12 DEM.

The topography in the region of interest shows a smooth surface, slightly sloping down to the west. One major feature is a transient ice divide, which splits $\sim 20 \mathrm{~km}$ upstream of the drilling location, thus separating three drainage basins. Of our 13 survey points, 12 are located between the two branches of the ice divide; only DML26 is located north of both ice branches (Fig. 4). As it represents a different drainage basin and flow regime, we exclude DML26 from further analysis. The ice divide and the local surface elevation are the largest factors determining the flow and strain field. This is evident from comparison of the mean slope direction at the drilling site with the mean flow direction of $273.5^{\circ}$ from the GPS-based velocity measurements. Small differences in magnitude and direction of the horizontal ice-flow velocities of the survey points are likewise mainly caused by the relative location of the survey point in respect to the ice divide. Points very close to the ice divide are generally slower and the direction of movement is nearly parallel to the course of the divide (Fig. 4 and Table 2, e.g. PEN1). The magnitude of the flow velocity increases with increasing distance from the divide, and the northward flow component is reduced (Fig. 4; Table 2). An exception is PEN5, which has a slightly lower velocity $\left(0.624 \mathrm{~m} \mathrm{a}^{-1}\right)$ than PEN1 $\left(0.643 \mathrm{~m} \mathrm{a}^{-1}\right)$ despite the greater distance from the divide. Although this difference is smaller than the estimated conservative maximum velocity error of $0.059 \mathrm{~m} \mathrm{a}^{-1}$, we try to identify the origin of this variation.

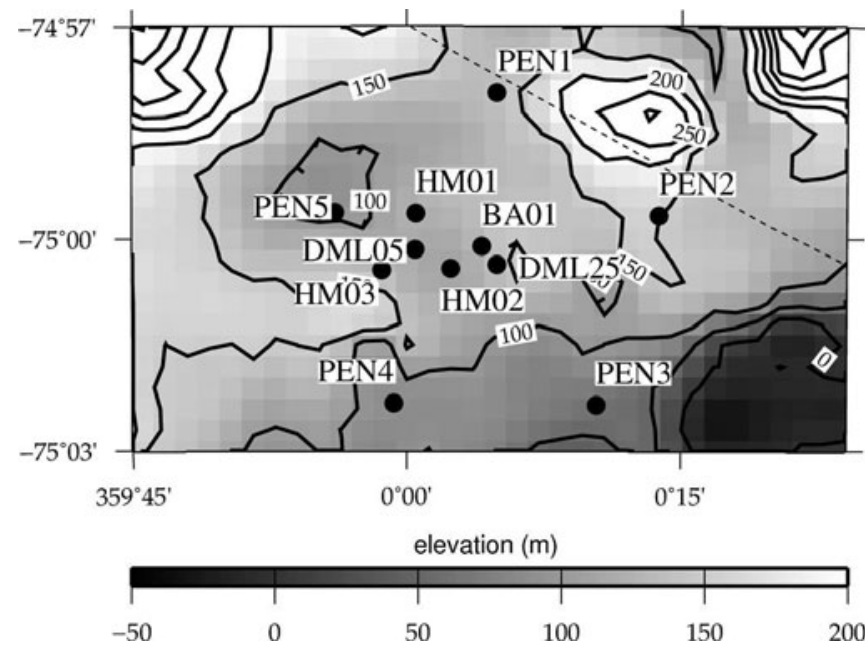

Fig. 7. Subglacial topography of the area of investigation gridded on a $500 \mathrm{~m} \times 500 \mathrm{~m}$ raster after Steinhage and others (1999). The spacing between the contours is $50 \mathrm{~m}$. The dotted line represents the ice divide corresponding to Bamber and Bindschadler (1997).

Investigating the local bedrock topography in the vicinity of PEN5, available from airborne radio-echo soundings (Steinhage and others, 1999), PEN5 is found to be located above a depression of the subglacial topography (Fig. 7). The depression is $\sim 5 \mathrm{~km}$ wide and several tens of meters deep, with respect to the surrounding average bedrock elevation. Because of the smoothing effect of ice dynamics, the surface elevation is much smoother than the bedrock topography. Surface topography varies only in the order of meters. The depression therefore simply causes locally increased ice thickness, but not a significant feature at the surface. The slightly lower velocity at PEN5, compared to the other stakes, is thus a consequence of the flux balance required by the larger ice thickness.

The surface strain rate at BA01, averaged from the strain triangles of the five pentagon points (PEN1-PEN5), is considered to be representative for the EDML ice core, as BA01 is only $93 \mathrm{~m}$ to the northeast of the drilling site. Most error estimates for the strain rates (Tables 3 and 4) are about equal to or smaller than the nominal value of the strain rate. For some strain rates with very small nominal values, the error is more than one order of magnitude larger (e.g. $\dot{\varepsilon}_{X}$ triangle 3, Table 4). We emphasize that the velocity errors are very conservative estimates, so the strain-rate errors are also conservative estimates. The average maximum principal component of the strain rate at BA01 is negative $(-1.85 \times$ $\left.10^{-4} \mathrm{a}^{-1}\right)$. It acts as a compressing force in the direction of $65.8^{\circ}$. The minimum principal component of the strain rate at BA01 is positive $\left(2.32 \times 10^{-5} \mathrm{a}^{-1}\right)$. It therefore corresponds to a dilatational force and acts along an axis in the direction of $155.8^{\circ}$. This results from the low magnitude of the velocity at PEN5. Both BA01 and PEN2 (upstream of PEN5) are moving faster than PEN5, which induces the along-flow compression of the ice mass. The average vertical strain rate, as calculated above, shows that the compression in the northwest-southeast direction only partly compensates the dilatational component of the strain field in the northeastsouthwest direction, perpendicular to the ice flow at EDML, and layer thinning is required in the vertical component to achieve balance. 


\section{CONCLUSION}

We provide an improved dataset for the surface topography and flow velocity in the vicinity of the EDML drilling site. A DEM of high accuracy was derived from a combination of kinematic surface GPS measurements and satellite laser altimetry from ICESat's GLAS12 data. Static GPS measurements at 13 stakes between the austral summer seasons 1997/98 and 2005/06 provided the basis for deriving the flow velocity field and resulting strain rates. The flow velocity field is, in general, divergent along the course of and in between the two branches of the ice divide. On top of this general field, small velocity variations are superimposed, which are caused by local variations in ice thickness resulting from undulations in bedrock topography. The horizontal strain field, calculated from the velocities, shows lateral extension and smaller longitudinal compression. This results in layer thinning in the EDML ice core, which has to be accounted for to yield a correct interpretation of ice-core data.

\section{ACKNOWLEDGEMENTS}

The data of GPS reference stations were allocated by A. Rülke of the Institute for Planetary Geodesy of the Technical University of Dresden (http://www.tu-dresden.de/ ipg/). Satellite altimetry data were provided by the US National Snow and Ice Data Center, Boulder, CO (http:// nsidc.org/data/icesat/). The authors thank D. Jansen for helpful discussions. This work is a contribution to the European Project for Ice Coring in Antarctica (EPICA), a joint European Science Foundation (ESF)/European Commission (EC) scientific program, funded by the EC and by national contributions from Belgium, Denmark, France, Germany, Italy, The Netherlands, Norway, Sweden, Switzerland and the UK. The main logistic support at Dronning Maud Land was provided by AWI. This is EPICA publication No. 177.
Preparation of this work was supported by Deutsche Forschumgsgemeinschaft with the 'Emmy Noether' scholarship EI-672/1 to O.E. This paper was enhanced significantly by the comments of M. King, R. Jacobel and R. Bindschadler.

\section{REFERENCES}

Bamber, J.L. and R.A. Bindschadler. 1997. An improved elevation dataset for climate and ice-sheet modelling: validation with satellite imagery. Ann. Glaciol., 25, 439-444.

Eisen, O., W. Rack, U. Nixdorf and F. Wilhelms. 2005. Characteristics of accumulation around the EPICA deep-drilling site in Dronning Maud Land, Antarctica. Ann. Glaciol., 41, 41-56.

EPICA Community Members. 2004. Eight glacial cycles from an Antarctic ice core. Nature, 429(6992), 623-628.

EPICA Community Members. 2006. One-to-one coupling of glacial climate variability in Greenland and Antarctica. Nature, 444(7116), 195-198.

Hvidberg, C.S., K. Keller and N.S. Gundestrup. 2002. Mass balance and ice flow along the north-northwest ridge of the Greenland ice sheet at NorthGRIP. Ann. Glaciol., 35, 521-526.

Paterson, W.S.B. 1994. The physics of glaciers. Third edition. Oxford, etc., Elsevier

Shuman, C.A. and 6 others. 2006. ICESat Antarctic elevation data: preliminary precision and accuracy assessment. Geophys. Res. Lett., 33(L7), L07501. (10.1029/2005GL025227.)

Steinhage, D., U. Nixdorf, U. Meyer and H. Miller. 1999. New maps of the ice thickness and subglacial topography in Dronning Maud Land, Antarctica, determined by means of airborne radio-echo sounding. Ann. Glaciol., 29, 267-272.

Vittuari, L. and 6 others. 2004. Space geodesy as a tool for measuring ice surface velocity in the Dome $\mathrm{C}$ region and along the ITASE traverse. Ann. Glaciol., 39, 402-408.

Wessel, P. and W.H.F. Smith. 1991. Free software helps map and display data. Eos, 72(41), 441, 445-446.

Zwally, H.J. and 15 others. 2002. ICESat's laser measurements of polar ice, atmosphere, ocean and land. J. Geodyn., 34(3-4), 405-445. 